\title{
Water scarcity footprint of hydropower based on a seasonal approach - Global assessment with sensitivities of model assumptions tested on specific cases
}

\author{
Stephan Pfister ${ }^{\mathrm{a}, *}$, Laura Scherer ${ }^{\mathrm{b}}$, Kurt Buxmann ${ }^{\mathrm{c}}$ \\ a Institute of Environmental Engineering, ETH Zurich, 8039 Zurich, Switzerland \\ ${ }^{\mathrm{b}}$ Institute of Environmental Sciences (CML), Leiden University, 2333 CC Leiden, the Netherlands \\ ${ }^{c}$ Route de Sion 28, CH-3960 Sierre, Switzerland
}

\section{H I G H L I G H T S}

- Reservoirs have a storing function and require monthly water scarcity assessments.

- Water storage during wet and release during dry seasons reduce water scarcity.

- Global analysis to 1473 hydropower plants covering $>100$ countries

- In many cases, evaporation is compensated by the storage effects for water scarcity.

- The two water scarcity metrics applied lead to large differences in water footprints.

\section{A R T I C L E I N F O}

\section{Article history:}

Received 30 November 2019

Received in revised form 25 February 2020

Accepted 23 March 2020

Available online 25 March 2020

Editor: Deyi Hou

\section{Keywords:}

Water scarcity footprint

Hydropower reservoir

Seasonality

Water consumption

Power production

\section{GRA P H I C A L A B S T R A C T}

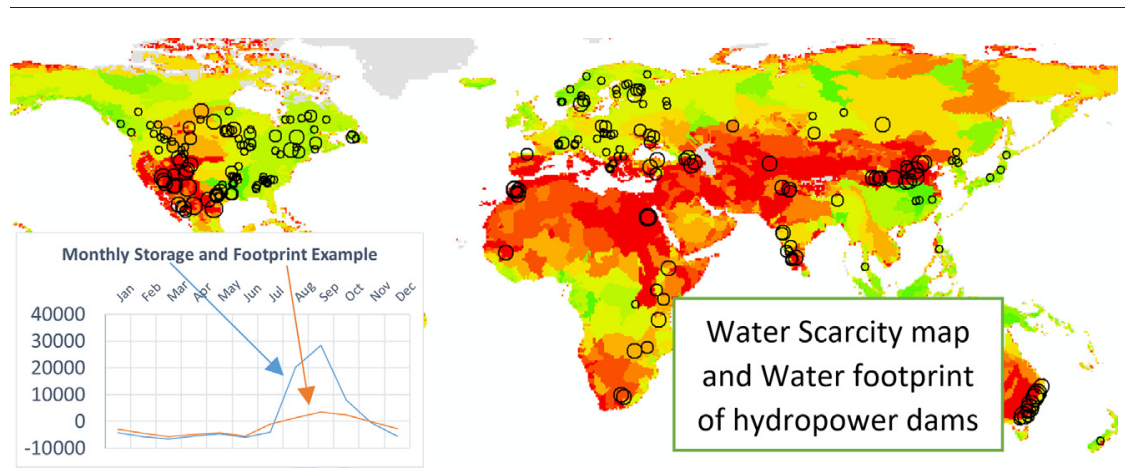

\section{A B S T R A C T}

According to ISO 14046 the quantification of the water scarcity footprint (WSFP) of hydropower reservoirs has to consider (1) the evaporation of water from the surface of the reservoir, (2) the baseline evaporation of water of the same area before the reservoir has been built, and (3) the water scarcity index of the location of the reservoir on a spatially and temporally explicit level.

When a reservoir has a storing function, e.g., for irrigation in the dry season, monthly water scarcity indexes have to be used in order to calculate the WSFP, since storage in wet seasons and release in dry seasons can counteract water scarcity and lead to a reduction of overall water scarcity in the watershed.

This paper builds on previous research regarding detailed hydropower modeling and extends the water scarcity assessment to include and advance new methods for identifying sensitivities in monthly WSFP of hydropower due to the choice of impact assessment methods. We applied the global analysis to 1473 hydropower plants covering $>100$ countries, and added a detailed assessment for a subset of important power plants to discuss the limitations of global assessments. We thereby provide the most complete WSFP of global hydropower with state-ofthe-art methods, assess the robustness of the global model and different methodological choices, and provide new monthly average AWARE CFs on watershed level.

The results show that water scarcity can often be mitigated if the net evaporation is compensated by the storage effects. The two water scarcity metrics applied lead to larger differences than expected, since the monthly

\footnotetext{
* Corresponding author.

E-mail address: pfister@ifu.baug.ethz.ch (S. Pfister).
} 
dynamics of dams can lead to stronger differences than the differences in the applied water scarcity factors. The new insights help to better understand the WSFP of hydropower and its uncertainties.

(C) 2020 Elsevier B.V. All rights reserved.

\section{Introduction}

Hydropower generation is generally classified as the second largest water consuming activity after irrigation (e.g. Mekonnen and Hoekstra, 2011), and provides $~ 16 \%$ of global power production in 2012. More than $50 \%$ of global hydropower is generated in China, Brazil, Canada and the United States (IEA, 2014). Hydropower has the highest water consumption per unit of electricity produced among major power production types, with estimates of $90 \mathrm{~m}^{3} / \mathrm{GJ}$ (Pfister et al., 2011) and $68 \mathrm{~m}^{3} / \mathrm{GJ}$ (Mekonnen and Hoekstra, 2011). The water consumption is defined as the gross evaporation from the reservoir surface. Previous research has highlighted that this is not the most appropriate approach, since water would evaporate from the natural water surface and surrounding ecosystems regardless of the reservoir's storage function. Thus net water consumption estimates have been provided for water scarcity footprint assessments (e.g. Pfister et al., 2011; ISO/TR 14073:2017, 2017; Buxmann et al., 2016; Herath et al., 2013; Scherer and Pfister, 2016a). This has been discussed in detail by Bakken et al. (2017) and Bakken et al. (2016).

Various data on hydropower water consumption are published in the literature. However, there has been limited work done on a global level. We have therefore based our research on both previous detailed global assessments for 1473 individual hydropower plants (Scherer and Pfister, 2016a) and a recent publication with 2235 reservoirs (Hogeboom et al., 2018). The latter calculates gross evaporation, but focuses on different methods for evaporation estimates and allocation to different uses of the reservoirs.

In order to assess water scarcity footprints (WSFP) based on ISO 14046 (ISO, 2013), monthly and spatially explicit characterization factors (CF) need to be applied to monthly water consumption of the reservoirs (ISO/TR 14073:2017, 2017). The same applies for assessing water consumption impacts within the framework of Life Cycle Assessment (LCA) (Buxmann et al., 2016; Pfister et al., 2015). Previous research on a global level (Scherer and Pfister, 2016a) used a modified approach of the water stress index (Pfister et al., 2009) and expanded it with an assessment of flow change impacts on ecosystem quality, which goes beyond the water scarcity footprint. In order to provide an analysis that can serve as a benchmark, we applied both the watershed level ( $>11,000$ units) recommended CFs of the UNEP working group "WULCA" (AWARE, Boulay et al., 2018) and the published CFs with the same resolution (WSI, Pfister and Bayer, 2014). As most CFs are to be used for marginal changes in water flows only and changes in runoff through hydropower might be non-marginal, we also applied average CFs to test the sensitivities of the scarcity assessment.

Additionally, we address the question of allocation between power production, irrigation and other reservoir purposes, which is a very sensitive step in the calculation of hydropower WSFP. Between monthly varying CF values and allocation assumptions, it is possible that hydropower WSFP estimates reported in previous scientific literature tend to overestimate the real water consumption and the resulting impacts on both water resource availability and the environment.

The objectives of this paper are to (1) provide the most complete water footprint assessment of global hydropower using state-of-the-art water scarcity assessment, (2) assess the robustness of the global model with a detailed assessment of important hydropower plants and different methodological choices, and (3) develop and provide average AWARE CFs to be applied for further assessments.

\section{Materials and methods}

\subsection{Global gross and net water consumption of hydropower plants}

We selected all 1473 hydropower plants from Scherer and Pfister (2016a) for this analysis, and used their monthly data for the inflows and outflows, as well as evaporation and seepage, in order to calculate the net water consumption (CS) for each month $\mathrm{t}$ :

$\mathrm{CS}(\mathrm{t})=\mathrm{IF}(\mathrm{t})+\mathrm{P}(\mathrm{t})-\mathrm{OF}(\mathrm{t})-\mathrm{AET}(\mathrm{t})-\mathrm{SP}(\mathrm{t})=\mathrm{NET}(\mathrm{t})+\mathrm{dS}(\mathrm{t})$

The annual net consumption represents the sum of monthly CS (t) values. IF is the inflow, P precipitation, OF outflow, SP seepage and AET is the actual evapotranspiration of the surrounding land cover, which is used as proxy for natural evapotranspiration at the location of the reservoir before its construction. NET is the net evapotranspiration and $\mathrm{dS}$ is the storage change. It has to be noted that this state-ofthe-art global data does not account for a detailed assessment of vegetation and reservoir dynamics and their effect on evapotranspiration.

We used the power generation from IEA (2014) and compared it to the installed capacity in the World Electric Power Plants Database (WEPP) database (Pfister et al., 2011). As a check, evaporation calculations were compared to the new total water consumption (gross evaporation) estimates of the total reservoir operation from the 529 matching entries of Hogeboom et al. (2018), based on the ID of the Global Reservoir and Dam (GRanD) database (Lehner et al., 2011) of each power plant, as both studies are using GRanD as a data source.

\subsection{Gross and net water consumption of selected major hydropower plants}

In order to check the robustness of our global assessment and provide specific data on major hydropower plants, we evaluated 13 large hydropower plants, which have been evaluated in a report published by the International Aluminium Institute (IAI) (Scherer and Pfister, 2015). These hydropower plants (compiled in Table 1), were evaluated to highlight the behavior of the scarcity assessment as a function of monthly CFs and evaluate the sensitivity of dam operation data.

\subsection{Allocation of water consumption to electricity production}

We applied the allocation factors (AF) from Scherer and Pfister (2016a), which are based on the ranking of reservoir purposes.

CS_allocated $=\mathrm{CS} \cdot \mathrm{AF}$

Additionally, we calculated the electricity value per hydropower plant based on the energy production at an average price of 0.1 USD/ kWh and compared it to the total value reported per dam by Hogeboom et al. (2018). From this, we derived value based AFs as the value share of the electricity. We also compared the hydropower plants with the allocated impacts from Hogeboom et al. (2018) based on the total evaporation and per GJ evaporation data for each dam. For the case of the High Aswan dam, we can directly use the allocation result shown in their paper per country, as it is the only one in Egypt.

\subsection{Water scarcity footprint assessment}

Water scarcity footprints need to be modeled on a spatially and temporally explicit level (ISO, 2013). For this, we multiplied CS(t) with monthly CFs on a watershed level (global coverage, $>11,000$ units) 
Table 1

Consulted databases and characteristics of selected reservoirs for the year 2009

\begin{tabular}{|c|c|c|c|c|c|c|}
\hline Dam & Countries & Database & Main purpose & Multi-purpose & Electricity (TWh) & Area/electricity $\left(\mathrm{km}^{2} / \mathrm{TWh}\right)$ \\
\hline Cahora Bassa & Mozambique & GRanD & Irrigation & Yes & 15.8 & 129.8 \\
\hline Aswan High & Egypt, Sudan & GRanD & Irrigation & Yes & 7.4 & 728.5 \\
\hline Three Gorges & China & GRanD & Hydropower & Yes & 79.9 & 10.7 \\
\hline Liujianxia & China & GRanD & Hydropower & Yes & 6.3 & 18.3 \\
\hline Laxiwa & China & GRanD & Hydropower & No & 2.1 & 2.1 \\
\hline Snowy Mountains & Australia & ANCOLD & Hydropower & Yes & 3.9 & 16.5 \\
\hline Tumut 3 & Australia & GRanD & Hydropower & No & 1.9 & 9.6 \\
\hline Murray 1 & Australia & GRanD & Hydropower & No & 0.7 & 0.4 \\
\hline Murray 2 & Australia & ANCOLD & Hydropower & No & 0.5 & 0.4 \\
\hline John Day & United States & GLWD & Hydropower & Yes & 8.4 & 7.4 \\
\hline Chief Joseph & United States & USGS & Hydropower & $\mathrm{No}^{\mathrm{a}}$ & 9.8 & 3.5 \\
\hline Grand Coulee & United States & GRanD & Irrigation & Yes & 21.0 & 12.8 \\
\hline The Dalles & United States & USGS & Hydropower & Yes & 6.1 & 7.9 \\
\hline
\end{tabular}

${ }^{\text {a }}$ Except for recreational purpose, which is excluded from allocation.

from the UNEP working group recommended marginal "AWARE"

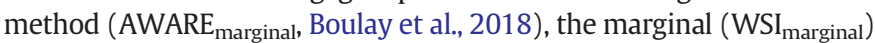
and average (WSI ${ }_{\text {avg }}$ ) CFs for monthly WSI (Pfister and Bayer, 2014), and the non-marginal AWARE CFs (AWARE ${ }_{\text {avg }}$ ), calculated as described below.

Both, AWARE and WSI are reporting $\mathrm{m}^{3} \mathrm{H}_{2} \mathrm{Oe} / \mathrm{m}^{3}$ water consumed. AWARE reports $\mathrm{H}_{2} \mathrm{Oe}$ in equivalents of the world average water availability situation (i.e. $\mathrm{m}^{2}$ area required to provide $1 \mathrm{~m}^{3} /$ year of water after environmental and human demand is met). The CFs range from 0.1 to 100 ( 1 being the world average water availability situation). WSI range from 0.01 to 1 and report $\mathrm{H}_{2} \mathrm{Oe}$ in equivalents of water consumed under extreme water scarcity. The total monthly water scarcity footprint ( WSFP $_{\text {dam }}$ ) and the WSFP per GJ electricity (WSFP ${ }_{\text {el }}$ ) are calculated based on annual electricity generation in GJ (AEG) as follows:

$\mathrm{WSFP}_{\mathrm{dam}}(\mathrm{t})=\mathrm{CS}(\mathrm{t}) \cdot \mathrm{CF}(\mathrm{t})$

$\mathrm{WSFP}_{\mathrm{el}}(\mathrm{t})=\mathrm{CS}(\mathrm{t}) \cdot \mathrm{CF}(\mathrm{t}) /(\mathrm{AEG} / 12) \cdot \mathrm{AF}$

For calculating the non-marginal AWARE CFs (AWARE ${ }_{\text {avg }}$ ) we integrated the scarcity function over the human consumption and divided by the human consumption (as done in Pfister and Bayer, 2014). We assume that the non-marginal changes of the individual hydropower plants do not affect the global reference significantly and thus we set it to a constant value based on Boulay et al. (2018). Thus, the integrated scarcity factor $\left(\mathrm{SF}_{\mathrm{avg}}\right)$ of $\mathrm{AWARE}_{\mathrm{avg}}$ before the normalization with the global reference and the cut-off can be calculated as follows:

$\mathrm{SF}_{\mathrm{avg}}=\left(\mathrm{A} \cdot \ln \left(\left|\mathrm{AMD}_{\text {natural }}\right|\right)-\mathrm{A} \cdot \ln \left(\left|\mathrm{AMD}_{\text {actual }}\right|\right)\right) / \mathrm{C}_{\text {human }}$,

where $A$ is the area of the watershed, AMD is availability minus demand, and demand includes human water consumption ( $\left.C_{\text {human }}\right)$ and environmental water requirements. Data is taken from Boulay et al. (2018). It is then normalized by the world average scarcity factor $\left(\mathrm{SF}_{\text {global }}\right)$ based on the original AWARE method to derive AWARE $\mathrm{avg}_{\mathrm{av}} \mathrm{CF}$. The normalized result $\left(\mathrm{SF}_{\mathrm{avg}} / \mathrm{SF}_{\text {global }}\right)$ is set to a $\mathrm{CF}$ of 100 , if $\mathrm{CF}>100$ or if $A M D_{\text {actual }} \leq 0$. In case of $C_{\text {human }}=0$, AWARE $_{\text {avg }}$ equals AWARE $_{\text {marginal }}$.

\section{Results}

\subsection{Global assessment}

The evaporation flows between the two papers used in the analysis match well (see SI), especially considering the large uncertainties in both the calculation of evaporation from various data sources as well as from the application of different evaporation equations, as shown by Hogeboom et al. (2018).

The gross and net water consumption for each power plant is reported in the supporting information, including monthly impact assessment results obtained using the described methods. Global total annual water consumption of all hydropower is calculated to be $4.4 \cdot 10^{11} \mathrm{~m}^{3}$ for net and $7.4 \cdot 10^{11} \mathrm{~m}^{3}$ for gross consumption. Net water consumption corresponds to $50 \%$ of crop water consumption based on Mekonnen and Hoekstra (2011) and indicates that hydropower net water consumption is the biggest water consumer after agriculture.

In general, the chosen impact assessment method has a very strong influence on the final result. This is largely due to the relatively high discrepancies in the monthly patterns for the tested CFs (e.g. only in $29 \%$ of all watersheds the month with highest CF matches for AWARE ${ }_{\text {avg }}$ and $W I_{a v g}$ ), in combination with the large monthly storage - even though AWARE and WSI generally correlate well on a global level (Pfister and Lutter, 2016). The main issue is that for hydropower water scarcity assessments with large storage activity, the differences among months are crucial, as this often decides whether the net WSFP is positive or negative. For nearly three quarters of the power plants (1074), results from the four sets of CFs applied (WSI ${ }_{a v g}$, WSI marginal, AWARE ${ }_{\text {avg }}$ and $A W A R E_{\text {marginal }}$ ) agreed on whether the result was net positive or negative. Of these unanimous results, 906 had a negative WSFP and 168 had a positive WSFP (i.e. an increasing water scarcity impact). The latter accounted for $19.5 \%$ of the power generated in the dataset. For the other 399 units, both negative and positive WSFP results were obtained among the different sets of CFs, thus a water scarcity footprint of 0 was assumed.

Globally, the water scarcity footprint of hydropower for those power plants with WSFP $>0$ (unanimously among the four sets of CFs) is shown in Table 2 based on energy production and allocation from Scherer and Pfister (2016a). It should be noted that AWARE ranges from 0.1 to 100 while WSI ranges from 0.01 to 1 , which means that AWARE results are generally a factor of 100 larger than WSI results: If we apply this factor to get AWARE-equivalent $\mathrm{m}^{3} \mathrm{H}_{2} \mathrm{Oe}$, we have 544 , $831,838,883 \mathrm{~m}^{3} \mathrm{H}_{2} \mathrm{Oe} / \mathrm{GJ}$ for $\mathrm{WSI}_{\mathrm{avg}}$, WSI marginal, AWARE $\mathrm{avg}_{\text {and }}$ and $A W A R E_{\text {marginal. }}$ The AWARE results are very close to each other and to the marginal WSI results, while WSI $_{\text {avg }}$ results are considerably lower. On global average, the sensitivity to the sets of CFs selected is therefore low (coefficient of variation is $20.0 \%$ ), but it can be significant on a case by case level, as discussed in Section 4.2. The average net water

Table 2

WSFP results for global assessment. Numbers are in $\mathrm{m}^{3} \mathrm{H}_{2} \mathrm{Oe} / \mathrm{GJ}$ electricity produced and based on those dams where all four sets of CFs agreed on a net scarcity impact (19.5\% of generated hydropower in the database).

\begin{tabular}{llllll}
\hline & $\begin{array}{l}\text { Net } \\
\text { ET }\end{array}$ & WSI $_{\text {avg }}$ & WSI $_{\text {marginal }}$ & AWARE $_{\text {avg }}$ & AWARE $_{\text {marginal }}$ \\
& 70.6 & 5.44 & 8.31 & 838 & 883 \\
\hline $\begin{array}{l}\text { Only positive WSFP } \\
\begin{array}{l}\text { Scaled to 100\% } \\
\quad \text { hydropower }\end{array}\end{array}$ & 13.7 & 1.06 & 1.62 & 163 & 172 \\
$\quad$ production & & & & & \\
\hline
\end{tabular}


consumption of power production with only positive WSFPs is $70.6 \mathrm{~m}^{3}$ / GJ. Scaling to the total power production in the dataset, the average net water consumption is $13.7 \mathrm{~m}^{3} / \mathrm{GJ}$. Fig. 1 presents a map of the WSFP results of all power plants analyzed in this study, using AWARE ${ }_{\text {avg }}$ CFs.

\subsection{Allocation}

The installed capacity of the 764 power plants with a match in the WEPP database (Pfister et al., 2011) was compared to the reported energy production used in this study (Scherer and Pfister, 2016a). We assumed the overall global capacity factor to be around 44\% (Scherer and Pfister, 2016a), while Hogeboom et al. (2018) assumed it to be $34 \%$. There is a significant mismatch of reported power production that can be partially explained by unknown operation types and annual fluctuations. The power production data vary between the two scientific studies on water footprint, even though the ratio of the allocated gross water consumption of Scherer and Pfister (2016a) over Hogeboom et al. (2018) is 1.80 for all matches (incl. allocation) and 3.75, for the 289 matches where no allocation is applied by Hogeboom et al. (SI, XLS, Table "global comparison"). The analyzed studies cover different years, but other factors might explain the difference, since the calculation of the gross ET deviates by a factor of almost 3 (Appendix).

\subsection{Detailed WSFP assessment of selected reservoirs}

In order to present the dynamics of monthly assessments and the use of more detailed data for estimating monthly water consumption, the results of monthly WSFP calculations for three of the 13 selected reservoirs (Cahora Bassa, Aswan High and Three Gorges) are shown in Tables 3-5. The detailed assessment of 13 dams is based on the report of Scherer and Pfister (2015) and the monthly water balance is compared to the global assessment.

The Cahora Bassa (Table 3) and High Aswan (Table 4) Dams show a different storage pattern in the detailed assessment, while the total water consumption is a good match between the global and detailed assessment. For the Three Gorges Dam (Table 5), the global pattern of monthly storage matches well with the detailed assessment. The difference in the temporal dynamics of storage in the dams leads to large differences in WSFP, especially for the High Aswan Dam. The comparison for the 13 dams assessed in detail with global data and an annual assessment show that the temporal resolution is of key importance, since total annual water consumption is generally a good match (Table 6). Table 6 also highlights the effect of the chosen CF to quantify the WSFP: While annual average assessments always produce a WSFP $>0$, the result of the monthly assessment using $\mathrm{WSI}_{\mathrm{avg}}$ is $<0$ for 12 of the 13 dams analyzed in the detailed assessment. The global assessment for the nine dams existing in the database shows two dams having a WSFP $>0$, i.e. there is one mismatch in the sign of the number between the global and local assessment (Aswan High Dam). In the other eight cases, the difference was within a factor of five (i.e. in the same order of magnitude) and for four of them, the difference was less than a factor two.

While, in general, WSFP calculated on a monthly level decreases the total annual WSFP due to storage, it can also have the opposite result, as is shown for the Liujianxia and Laxiwa dams using the AWARE avg $_{\text {CFs }}$ (see SI); the monthly storage and release is much larger than the annual net consumption and as the AWARE $\mathrm{Avg}_{\text {ang }}$ indicates higher scarcity during the storage periods than during the release, the monthly WSFP is 200 times higher than the WSFP calculated at the annual level for the Laxiwa dam.

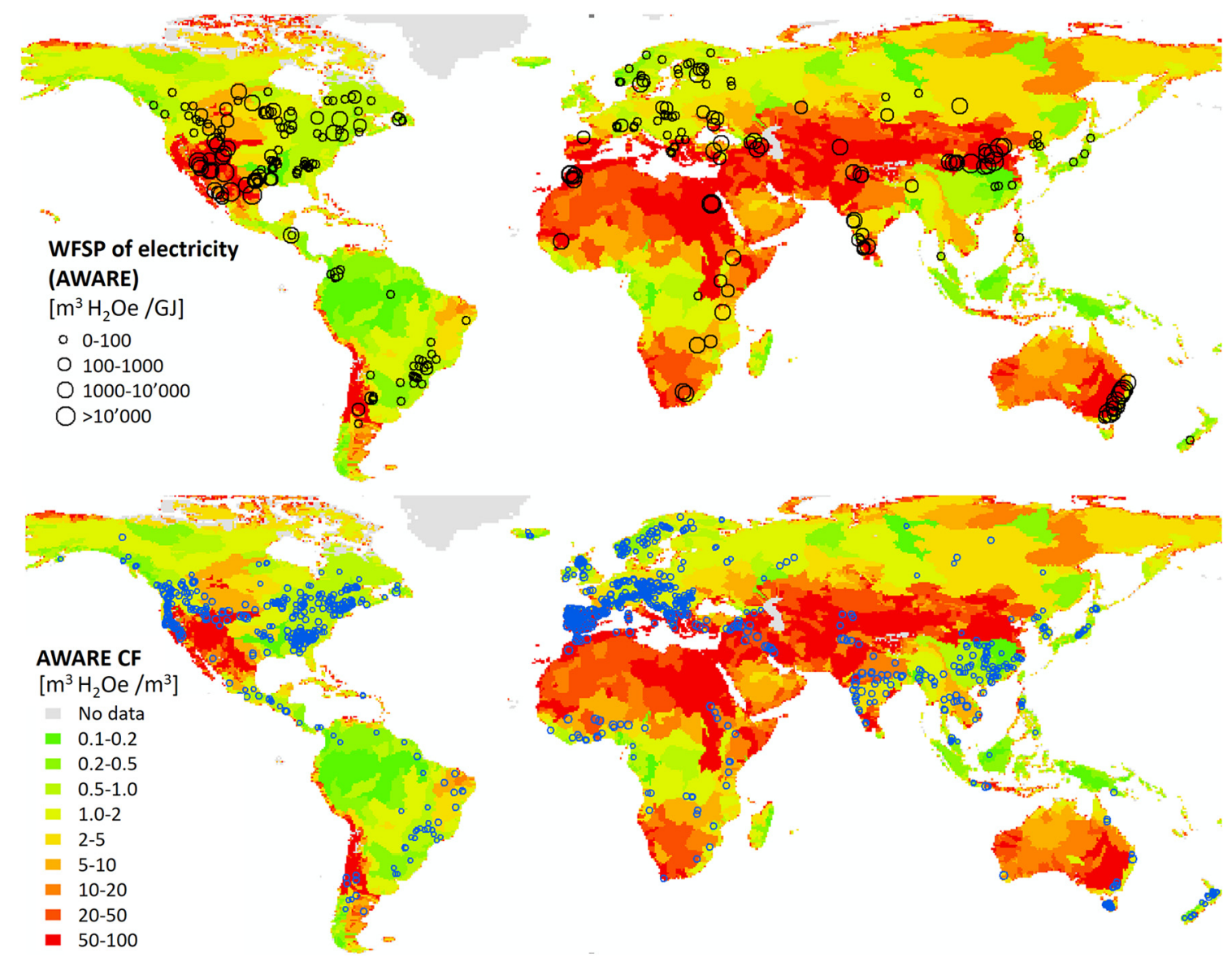

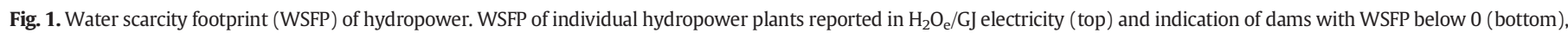

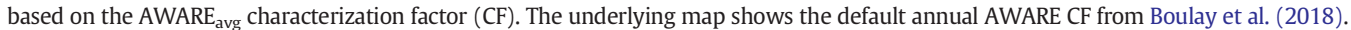


Table 3

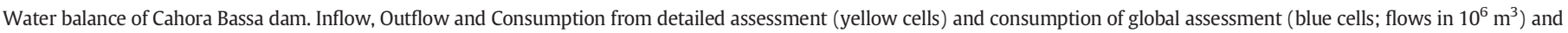
WSFP using different characterization factors in $10^{6} \mathrm{~m}^{3} \mathrm{H}_{2} \mathrm{O}_{\mathrm{e}}$ (red cells).

\begin{tabular}{|c|c|c|c|c|c|c|c|c|}
\hline \multirow[b]{2}{*}{ Month } & \multirow[b]{2}{*}{ Inflow } & \multirow[b]{2}{*}{ Outflow } & \multicolumn{2}{|c|}{ Net Consumption } & \multicolumn{4}{|c|}{ Footprints (WSFP) } \\
\hline & & & Detailed & Global & AWARE $_{\text {marginal }}$ & AWARE $_{\mathrm{avg}}$ & $\mathrm{WSI}_{\text {marginal }}$ & $\mathrm{WSI}_{\mathrm{avg}}$ \\
\hline Jan & 16261 & 10900 & 5591 & -294 & 11434 & 11409 & 56.2 & 56.1 \\
\hline Feb & 11074 & 10844 & 141 & -8056 & 279 & 277 & 1.4 & 1.4 \\
\hline Mar & 18430 & 16772 & 1524 & -5893 & 3689 & 3637 & 15.3 & 15.3 \\
\hline Apr & 8180 & 6041 & 1843 & 4537 & 8893 & 8566 & 18.7 & 18.6 \\
\hline May & 5711 & 2207 & 3185 & 3922 & 39118 & 36683 & 32.6 & 32.2 \\
\hline Jun & 4745 & 3012 & 1394 & 4123 & 20706 & 20572 & 14.5 & 14.2 \\
\hline Jul & 4271 & 5437 & -1489 & 2171 & -18050 & -17955 & -15.9 & -15.4 \\
\hline Aug & 3745 & 7317 & -3921 & 707 & -42051 & -41853 & -44.6 & -41.8 \\
\hline Sep & 3157 & 4930 & -2112 & 2448 & -20500 & -20413 & -27.0 & -23.9 \\
\hline Oct & 3166 & 3348 & -531 & 2959 & -3851 & -3839 & -8.2 & -6.7 \\
\hline Nov & 3667 & 5275 & -1852 & -1417 & -10655 & -10627 & -26.6 & -22.3 \\
\hline Dec & 5847 & 5421 & 457 & -1405 & 1651 & 1648 & 4.6 & 4.6 \\
\hline Total & & & 4230 & 3802 & -9337 & -11896 & 21.1 & 32.2 \\
\hline
\end{tabular}

\subsection{Country average hydropower WSFP}

We calculated the national average WSFP of hydropower based on the allocation of dams to countries. The results are presented in the SI. These can be used to calculate impacts of electricity use in background databases. The difference between countries is very high (over several orders of magnitude) for all indicators (see SI, XLS: "country avg results"). This shows the importance of using at least country-specific WSFP results based on highly detailed assessments, as provided in this study, since current implementations of water flows in background databases do not fulfill the ISO 14046 requirements (Pfister et al., 2015).

\section{Discussion}

\subsection{Global assessment}

The WSFP quantifies the contribution of a process, in this case of a hydropower reservoir, to water scarcity. If the WSFP is calculated on a monthly basis, the resulting number is in most of the cases negative.
This demonstrates that, because of its operation, the reservoir has a positive effect on water scarcity, especially when more water is collected than released in the wet season and more water is released than collected in the dry season. It is debatable whether negative impacts, i.e. benefits, should be reported as such or set to zero, since the uncertainty of dam operation and thus monthly storage is high in global assessments (as shown in Table 6), and if there is a large negative WSFP, the main purpose is likely storage for irrigation. Additionally, variability of water inflow and water demand affect dam operation among years. We suggest to set WSFP for these cases to zero. For calculating country or global averages, we suggest to sum the WSFP of dams with WSFP $>0$ and divide it by the total hydropower production of all dams (see Table 2 and SI for country averages). Therefore, our WSFP results are much lower compared to previous studies. As a consequence, the water consumption results reported in background databases should be adjusted, as long as they do not report the values on a monthly level.

From the global analysis, no clear relation between WSFP of dams and the average annual water scarcity in the watershed are observed, as positive and negative WSFP occur in low and high scarcity regions

Table 4

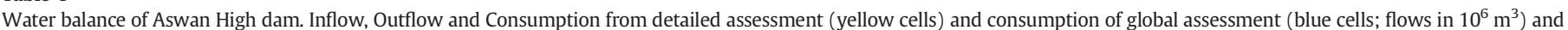
WSFP using different characterization factors in $10^{6} \mathrm{~m}^{3} \mathrm{H}_{2} \mathrm{O}_{\mathrm{e}}$ (red cells).

\begin{tabular}{|c|c|c|c|c|c|c|c|c|}
\hline \multirow[b]{2}{*}{ Month } & \multirow[b]{2}{*}{ Inflow } & \multirow[b]{2}{*}{ Outflow } & \multicolumn{2}{|c|}{ Net Consumption } & \multicolumn{4}{|c|}{ Footprints (WSFP) } \\
\hline & & & Detailed & Global & AWARE $E_{\text {marginal }}$ & AWARE $_{\text {avg }}$ & $\mathrm{WSI}_{\text {marginal }}$ & $\mathrm{WSI}_{\text {avg }}$ \\
\hline Jan & 4134 & 6881 & -4273 & 1287 & -427300 & -427300 & $-4,272.8$ & $-2,915.6$ \\
\hline Feb & 2134 & 6512 & -5757 & 1175 & -575700 & -575700 & $-5,757.0$ & $-4,505.4$ \\
\hline Mar & 1393 & 6525 & -6658 & 1338 & -665800 & -665800 & $-6,658.0$ & $-5,704.2$ \\
\hline Apr & 1492 & 5515 & -5499 & 1434 & -549900 & -549900 & $-5,499.0$ & $-4,920.1$ \\
\hline May & 2620 & 5766 & -4670 & 1478 & -467000 & -467000 & $-4,670.0$ & $-4,297.7$ \\
\hline Jun & 3008 & 7525 & -5994 & 1376 & -599400 & -599400 & $-5,994.0$ & $-5,548.5$ \\
\hline Jul & 7106 & 9639 & -4060 & 1397 & -406000 & -406000 & $-3,197.3$ & $-1,058.0$ \\
\hline Aug & 32917 & 11040 & 20351 & 1424 & 2035100 & 2035100 & $4,541.6$ & $1,474.0$ \\
\hline Sep & 40336 & 10484 & 28375 & 1407 & 2837500 & 2837500 & $11,702.1$ & $3,490.3$ \\
\hline Oct & 15666 & 6026 & 8113 & 1421 & 811300 & 811300 & $7,010.8$ & $2,500.0$ \\
\hline Nov & 6956 & 6063 & -585 & 1281 & -58500 & -58500 & -540.6 & -211.8 \\
\hline Dec & 2486 & 6369 & -5410 & -834 & -541000 & -541000 & $-5,349.0$ & $-2,669.5$ \\
\hline Total & & & 13933 & 14183 & 1393300 & 1393300 & $-18,683.1$ & $-24,366.3$ \\
\hline
\end{tabular}


Table 5

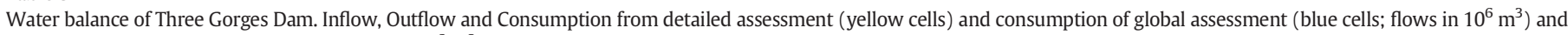
WSFP using different characterization factors in $10^{6} \mathrm{~m}^{3} \mathrm{H}_{2} \mathrm{O}_{\mathrm{e}}$ (red cells).

\begin{tabular}{|c|c|c|c|c|c|c|c|c|}
\hline \multirow[b]{2}{*}{ Month } & \multirow[b]{2}{*}{ Inflow } & \multirow[b]{2}{*}{ Outflow } & \multicolumn{2}{|c|}{ Net Consumption } & \multicolumn{4}{|c|}{ Footprints (WSFP) } \\
\hline & & & Detailed & Global & AWARE $E_{\text {marginal }}$ & AWARE $_{\text {avg }}$ & $\mathrm{WSI}_{\text {marginal }}$ & $\mathrm{WSI}_{\mathrm{avg}}$ \\
\hline Jan & 9625 & 19065 & -9599 & -7886 & -18966 & -17874 & -138.8 & -116.1 \\
\hline Feb & 8853 & 18612 & -9869 & -8212 & -24607 & -23152 & -201.9 & -144.3 \\
\hline Mar & 11331 & 20065 & -8848 & -7213 & -19657 & -18577 & -439.8 & -220.3 \\
\hline Apr & 30581 & 31343 & -801 & 456 & -1424 & -1348 & -82.7 & -32.6 \\
\hline May & 32999 & 32760 & 237 & 1357 & 240 & 221 & 32.5 & 11.8 \\
\hline Jun & 42584 & 38376 & 4228 & 5225 & 2436 & 2304 & 69.9 & 55.0 \\
\hline Jul & 70287 & 54607 & 15622 & 9879 & 5203 & 5021 & 182.1 & 168.9 \\
\hline Aug & 75691 & 57773 & 17889 & 9872 & 5078 & 4935 & 199.8 & 189.2 \\
\hline Sep & 51504 & 43602 & 7842 & 8727 & 2452 & 2419 & 85.2 & 81.8 \\
\hline Oct & 31490 & 31876 & -520 & 771 & -204 & -201 & -5.8 & -5.5 \\
\hline Nov & 16600 & 23152 & -6667 & -5126 & -4985 & -4856 & -79.9 & -73.1 \\
\hline Dec & 11270 & 20028 & -8909 & -7246 & -12637 & -12075 & -112.7 & -100.4 \\
\hline Total & & & 605 & 605 & -67071 & -63182 & -492.0 & -185.6 \\
\hline
\end{tabular}

(Fig. 1). However, high WSFP of dams mainly occur in water scarce areas.

\subsection{Sensitivities}

There is a high uncertainty of hydropower WSFPs due to several aspects, including the spatial and temporal variations, as is shown in our comparison of global assessment with local detailed assessments. Additionally, actual climate variation between years and especially in the future is increasing uncertainties, since hydropower dams are long-living infrastructures. On the inventory side (i.e. water consumption), it is important to capture the specific local conditions to properly quantify evaporation losses. This has been discussed in detail by Hogeboom et al. (2018) and the effect is presented in Fig. 2. More importantly, based on our comparison with local and global data is the monthly pattern of the storage and release, which is based on limited data availability for the global model as discussed in Scherer and Pfister (2016a). This means to better assess the monthly inventory of hydropower dams, better operation data is necessary.

The choice of water scarcity CFs has a significant effect at the dam level, as shown in the detailed assessment and in Fig. 2, even if on the global average, the two methods are quite consistent. The difference between marginal and average CFs is less significant than between AWARE and WSI, which indicates that the average factors are not that important, even though they reduce the impact in general (Fig. 2). The effect is stronger for WSI than AWARE, which might be a result of the cut-off choice at a factor of 100 in AWARE (see Section 4.3). However, based on the UNEP consensus report on AWARE (Jolliet et al., 2018), marginal CFs should only be applied to conditions with up to $5 \%$ change in overall water consumption. For hydropower reservoirs, this can be equated to $5 \%$ change in water availability, since the inflow is temporally stored (i.e. consumed) and the outflow is negative consumption. This approach also allows for a more specific assessment of a dam, since relating the net storage to total net water consumption in the watershed neglects the location of the dam within a watershed. The analysis of the detailed dams shows, that in $85 \%$ of all months of the selected reservoirs, the storage was $>5 \%$ compared to the inflow ( $\mathrm{SI}$, XLS, Table "Detailed Assessment"). These results suggest to generally apply average CFs for hydropower dams.

Although allocation is important in LCA and water footprinting in general, it is particularly important for hydropower given the multipurpose function of dams (Fig. 2). The water is typically used for two or three processes, i.e. irrigation and/or municipal water supply and generation of electricity. This can be considered an allocation issue at the inventory level. Power production and water supply are joint processes, i.e. the quantity of water used for the generation of electricity and the quantity used for irrigation and municipal supply cannot be varied independently. According to ISO 14044, it is appropriate to apply a

Table 6

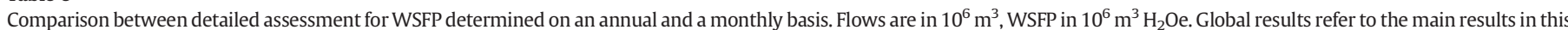
paper, indicating the relevance of specific input data in the local assessments (mainly related to dam operation). Results using average CFs are presented in bold.

\begin{tabular}{|c|c|c|c|c|c|c|c|c|}
\hline \multirow[t]{2}{*}{ Reservoir } & \multicolumn{2}{|l|}{ Net consumption } & \multicolumn{4}{|c|}{ WSFP, detailed monthly assessment } & \multirow{2}{*}{$\frac{\text { Annual CF }}{\text { WSI }_{\text {avg }}}$} & \multirow{2}{*}{$\frac{\text { Global results }}{\text { WSI }_{\mathrm{avg}}}$} \\
\hline & Detailed results & Global results & AWARE $_{\text {marginal }}$ & AWARE $_{\text {avg }}$ & WSI marginal $_{1}$ & $\mathrm{WSI}_{\mathrm{avg}}$ & & \\
\hline Cahora Bassa & 4230 & 3802 & -9337 & $-11,896$ & 21 & 32 & 45 & 48 \\
\hline High Aswan Dam & 13,933 & 14,183 & $1,393,300$ & $1,393,300$ & $-18,683$ & $-24,366$ & 7758 & 7991 \\
\hline Three Gorges Dam & 605 & 605 & $-67,071$ & $-63,182$ & -492 & -186 & 11 & -82 \\
\hline Liujianxia & 172 & 187 & 79,959 & 85,252 & 89 & -250 & 89 & -191 \\
\hline Laxiwa & 5 & 11 & 65,834 & 72,146 & -50 & -232 & 3 & -132 \\
\hline Snow Mountains/Blowering & 99 & NA & NA & NA & -40 & -29 & 36 & -57 \\
\hline Tumut 3/Talbingo & 18 & 18 & -410 & -1189 & -40 & -30 & 7 & -6 \\
\hline Murray $1 /$ Geehi & 0.3 & 0.3 & -1542 & -1893 & -22 & -16 & 0.1 & -6 \\
\hline Murray 2 & 0.2 & 3 & -1529 & -1876 & -22 & -16 & 0.1 & -5 \\
\hline John Day & 86 & NA & $-10,396$ & -7150 & -2923 & -914 & 4 & NA \\
\hline Chief Joseph & 41 & NA & -3277 & -2887 & -773 & -247 & 2 & NA \\
\hline Grand Coulee & 262 & NA & -3574 & 1530 & -1737 & -488 & 14 & NA \\
\hline The Dalles & 46 & NA & $-11,649$ & -7952 & -3252 & -1016 & 2 & NA \\
\hline
\end{tabular}




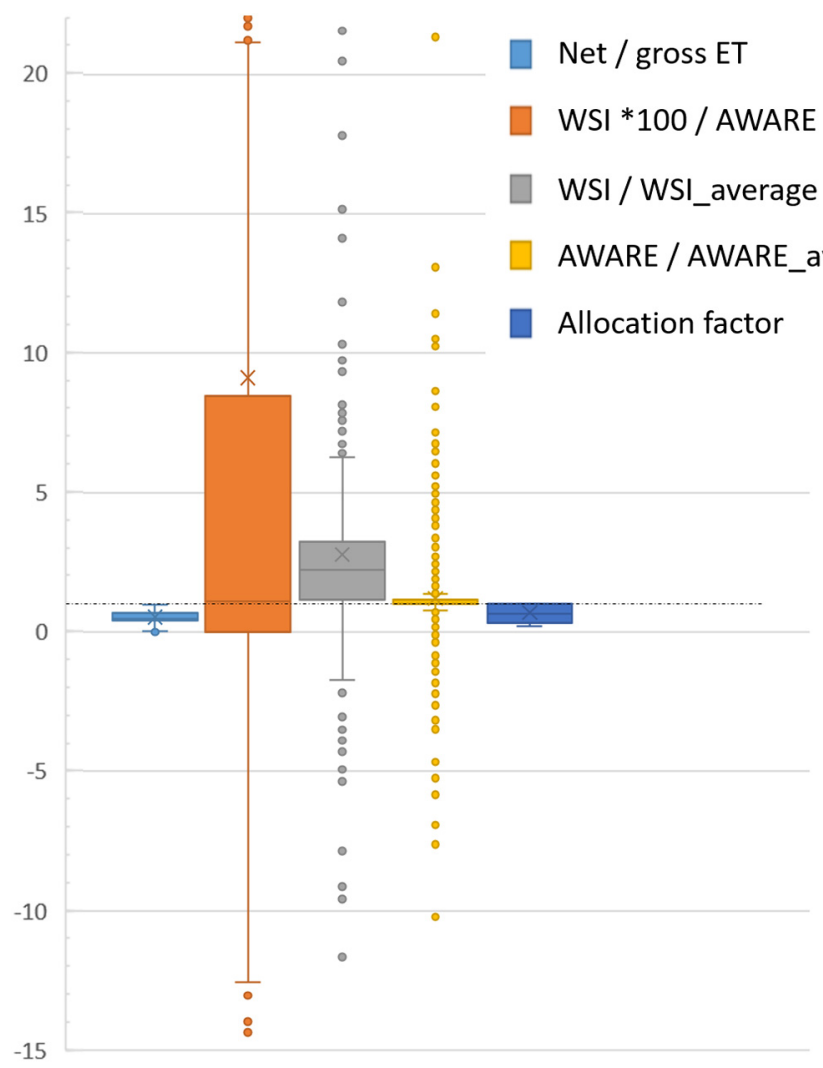

Fig. 2. Effect of choices to calculate WSFP of hydropower. Boxplot of the ratios between WSFP of individual hydropower plants when applying different input data: Net ET / gross ET for the water consumption estimate, different methods for characterization factors (CFs), and with or without an allocation factor. For the choice of CFs we report the ratio of WSI (multiplied by a factor of 100 to adjust for the different scales) and AWARE on a marginal level (WSI $* 100$ / AWARE), as well as the ratio between marginal and average CFs for WSI (WSI / WSI_average) and AWARE (AWARE / AWARE_avg).

market value allocation, especially if there is not a chemically or physically meaningful relation among the different purposes. This means that for the location of each reservoir the average market price per $\mathrm{kWh}$ of electricity and the market price for the supply of $1 \mathrm{~m}^{3}$ of water should be known.

In the allocation procedure based on economic value following Hogeboom et al. (2018), the electricity production gets a rather small impact share (see SI; "global comparison"), which is in line with the country average shares they reported (the large share of power plants of their analysis are in China and the US, which mainly have allocation to other uses). In principle, allocation can also be done on the monthly level, since in reality the value of both electricity and irrigation water depends on the market. Thus, the mitigating effect on water scarcity will be mainly driven by non-power demands (i.e. water supply and flood control). This reflects potential improvement of operations to further decrease water scarcity, but economic reasons lead to a combined operation scheme that accounts for all purposes. Therefore, allocation needs to be done carefully and the involved uncertainties clearly discussed. Compared to the monthly vs annual impact assessment and the modeling of monthly water flows, allocation has been of lower importance. Still, future research should include better information of economic values for the different purposes.

\subsection{Effect of limiting AWARE CFs to 100 (cut-off) and of the global reference}

The detailed assessment of specific dams showed that AWARE CFs (marginal and average) are at 100 in all months for the case of Aswan High Dam and thus the WSFP is 100 times the net consumption (Table 4). On the other hand, WSI vary over the season: the WSI CF was below 1 from August to October, when the inflow is significantly higher than the outflow. This resulted in a positive WSFP parameter for AWARE and a negative WSFP result for WSI. The difference is due to the fact that AWARE takes into account natural water scarcity per area and has a cut-off at 100 . The natural water scarcity is high in the Nile watershed, and thus water storage and release dynamics of dams have no effect at the chosen cut-off, which can be considered a limitation of the cut-off approach chosen by the AWARE method. Additionally, the cut-off also depends on the global average used as a reference.

However, applying average AWARE CFs calculated by an alternative calculation procedure suggested by Boulay et al. (2019) would lead to a negative water footprint for the Nile, too. This is due to the fact that they calculate average AWARE CFs, by integrating the marginal CFs after the cut-off, instead of deriving average impacts from the water scarcity impact function as done in this work. Additionally, several issues in the equations and thus results presented in Boulay et al. (2019) have to be noted: (1) they do not consider the impact of the non-marginal water consumption on the global reference value, which is affected especially if countries or large regions are assessed as a whole (in this work, we assumed the effect to be minor, since single reservoirs have a low influence on the global reference value); (2) they seem to double-count the impact of water consumption below the lower threshold; (3) the equation they present in the Appendix for the integral solution between the cut-off values seems to have sign errors for availability and demand. Therefore, caution is advised in using the average CFs from Boulay et al. (2019).

\subsection{Other environmental impacts}

A comprehensive water footprint based on ISO 14046 also needs to consider quality changes (ISO, 2013). This study is restricted to the WSFP, i.e. the contribution of a hydropower reservoir to water scarcity, without consideration of other potential environmental impacts of the reservoir, e.g. to biodiversity, climate change, acidification, eutrophication or ecotoxicity. Therefore, the results cannot be used for claims on an overall environmental burden or benefit or a full water footprint based on ISO 14046. Dams change flow dynamics that affect ecosystems, as quantified by Scherer and Pfister (2016a), and these effects could be mitigated by adjusting operations (Richter and Thomas, 2007). Additionally, dams also change temperature and sediment flows that affect nutrient and other characteristics of water quality, and should be addressed separately. This is required on a case by case basis, since methods in LCA are still missing on a global level. Finally, flooding of terrestrial ecosystems causes land use and land use change impacts (Dorber et al., 2018) and all factors contribute to greenhouse gas emissions (Scherer and Pfister, 2016b).

\section{Conclusions}

This study shows that many hydropower reservoirs, especially those which store water in the wet season and release water in the dry season, can be considered as beneficial in terms of water scarcity if the water scarcity footprint is calculated based on seasonal water scarcity indexes. However, this study was the first to analyze the effect of different water scarcity metrics, as recommended by the water scarcity footprint UNEP working group (Jolliet et al., 2018). The results show the high uncertainty arising from the methodological choice. For more than a quarter of the power plants the sign of impact does not agree among the tested water scarcity characterization methods, while the global average results varied by a factor 1.6 between the minimum and maximum WSFP estimates.

Nevertheless, while hydropower is identified as having a large share of human induced net blue water consumption ( $~ 50 \%$, see above), the impact in terms of water scarcity is generally low: the WSFP of global hydropower is $<3 \%$ of the WSFP of global crop production (Pfister and Bayer, 2014), both measured by WSI $_{\text {avg. }}$. The developed approach can 
be used to assess additional hydropower scheme in more detail or to evaluate potential hydropower plants, such as those analyzed by Hoes et al. (2017), in order to assess potential impacts of hydropower expansion.

The main limitations are related to the lack of data on the operation of hydropower dams, which is depending on natural water availability as well as demand for power and other services of the dam (e.g. water supply and flood protection).

Future research should therefore address the regime of hydropower dams in more detail. A special focus should be set on cascades of hydropower dams, since they should be addressed as systems rather than individual power plants.

\section{CRediT authorship contribution statement}

Stephan Pfister: Conceptualization, Methodology, Writing - original draft. Laura Scherer: Conceptualization, Methodology, Writing - review \& editing. Kurt Buxmann: Conceptualization, Writing - review \& editing.

\section{Declaration of competing interest}

The authors declare that they have no conflict of interest.

\section{Acknowledgements}

We thank Pernelle Nunez (IAI) and Christie Walker (ETHZ) for useful comments on the paper and Anne-Marie Boulay for discussing nonmarginal CFs and sharing data on AWARE from a paper submitted in parallel to this work. Supporting data to reproduce the study and additional results are available within the Supporting information.

\section{Appendix A. Supplementary data}

The Supporting information contains an Appendix with additional methods and results and an XLSX-file with the input data and additional detailed results. Supplementary data to this article can be found online at https://doi.org/10.1016/j.scitotenv.2020.138188.

\section{References}

Bakken, T.H., Modahl, I.S., Raadal, H.L., Bustos, A.A., Arnoy, S., 2016 Aug 1. Allocation of water consumption in multipurpose reservoirs. Water Policy 18 (4), 932-947. https://doi.org/10.2166/wp.2016.009 Internet. cited 2018 Jun 22.

Bakken, T.H., Killingtveit, A., Alfredsen, K., 2017. The water footprint of hydropower production-state of the art and methodological challenges. Glob. Chall. 1 (5) 1600018. https://doi.org/10.1002/gch2.201600018 [Internet]. Aug [cited 2018 Jun $22]$.

Boulay, A., Bare, J., Benini, L., et al., 2018. The WULCA consensus characterization model for water scarcity footprints: assessing impacts of water consumption based on available water remaining (AWARE). Int. J. Life Cycle Assess. 23, 368-378. https://doi.org/ 10.1007/s11367-017-1333-8.

Boulay, A.M., Benini, L., Sala, S., 2019. Marginal and non-marginal approaches in characterization: how context and scale affect the selection of an adequate characterization model. The AWARE model example. Int. J. Life Cycle Assess. https://doi.org/10.1007/ s11367-019-01680-0 Available from: 9.

Buxmann, K., Koehler, A., Thylmann, D., 2016. Water scarcity footprint of primary aluminium. Int. J. Life Cycle Assess. 21 (11), 1605-1615. https://doi.org/10.1007/s11367015-0997-1 [Internet]. Nov 29 [cited 2018 Jun 22].

Dorber, M., May, R., Verones, F., 2018 Feb 20. Modeling net land occupation of hydropower reservoirs in Norway for use in life cycle assessment. Environ. Sci. Technol 52 (4), 2375-2384. https://doi.org/10.1021/acs.est.7b05125 Internet. cited 2018 Jun 22.

Herath, I., Green, S., Horne, D., Singh, R., McLaren, S., Clothier, B., 2013. Water footprinting of agricultural products: evaluation of different protocols using a case study of New Zealand wine. J. Clean. Prod. 44 (0), 159-167 [Internet]. Available from. http:// www.sciencedirect.com/science/article/pii/S0959652613000139.

Hoes, O.A.C., Meijer, L.J.J., van der Ent, R.J., van de Giesen, N.C., 2017. Systematic highresolution assessment of global hydropower potential. PLoS One 12 (2), e0171844. https://doi.org/10.1371/journal.pone.0171844 [Internet]. Feb 8 [cited 2019 Feb 20]. (Deng ZD, editor).

Hogeboom, R.J., Knook, L., Hoekstra, A.Y., 2018. The blue water footprint of the world's artificial reservoirs for hydroelectricity, irrigation, residential and industrial water supply, flood protection, fishing and recreation. Adv. Water Resour. 113, 285-294 Internet. Mar 1 [cited 2018 Jun 22. Available from:. https://www.sciencedirect.com/ science/article/pii/S030917081730307X.

IEA, 2014. Key World Energy Statistics. International Energy Agency, Paris.

ISO, 2013. ISO/DIS 14046 water footprint - principles, requirements and guidelines. Internet. Available from. http://www.iso.org/iso/catalogue detail?csnumber $=43263$.

ISO/TR 14073:2017, 2017. Environmental management - water footprint - illustrative examples on how to apply ISO 14046. Available from. https://www.iso.org/standard/72264.html.

Jolliet, O., Antón, A., Boulay, A.M., Cherubini, F., Fantke, P., Levasseur, A., et al., 2018. Global guidance on environmental life cycle impact assessment indicators: impacts of climate change, fine particulate matter formation, water consumption and land use. Int. J. Life Cycle Assess. 2018. https://doi.org/10.1007/s11367-018-1443-y.

Lehner, B., Catherine, R.L., Revenga, C., Vörösmarty, C., Fekete, B., Crouzet, P., et al., 2011 High-resolution mapping of the world's reservoirs and dams for sustainable riverflow management. Front. Ecol. Environ. 9 (9), 494-502. https://doi.org/10.1890/ 100125 Internet. May 31.

Mekonnen, A.Y., Hoekstra, M.M., 2011. The water footprint of electricity from hydropower. Value of Water Research Report Series. UNESCO-IHE.

Pfister, S., Bayer, P., 2014. Monthly water stress: spatially and temporally explicit consumptive water footprint of global crop production. J. Clean. Prod. 73 (0), 52-62 [Internet]. Available from. http://www.sciencedirect.com/science/article/pii/ S0959652613007956.

Pfister, S., Lutter, S.F., 2016. How EU27 is outsourcing the vast majority of its land and water footprint. LCA Food 2016 , pp. 838-841 Internet. Available from. http://www. lcafood2016.org/wp-content/uploads/2016/10/LCA2016_BookOfAbstracts.pdf.

Pfister, S., Koehler, A., Hellweg, S., 2009. Assessing the environmental impacts of freshwater consumption in LCA. Environ. Sci. Technol. 43 (11), 4098-4104. https://doi.org/ 10.1021/es802423e Internet.

Pfister, S., Saner, D., Koehler, A., 2011. The environmental relevance of freshwater consumption in global power production. Int. J. Life Cycle Assess. 16 (6).

Pfister, S., Vionnet, S., Levova, T., Humbert, S., 2015. Ecoinvent 3: assessing water use in LCA and facilitating water footprinting. Int. J. Life Cycle Assess. https://doi.org/ 10.1007/s11367-015-0937-0.

Richter, B.D., Thomas, G.A., 2007. Restoring environmental flows by modifying dam operations. Ecol. Soc. 12 (1) Internet. Available from:. https://www.ecologyandsociety. org/vol12/iss1/art12/.

Scherer, L, Pfister, S, 2015. Water scarcity footprint of selected hydropower reservoirs. [Internet]. Available from. http://www.world-aluminium.org/media/filer_public/ 2015/12/02/324-150901-eth_esd_water_footprint_hydropower_final.pdf.

Scherer, L., Pfister, S., 2016a. Global water footprint assessment of hydropower. Renew. Energy 99.

Scherer, L., Pfister, S., 2016b. Hydropower's biogenic carbon footprint. PLoS One 11 (9). 